\title{
Article \\ Effectiveness of Lifestyle Modification vs. Therapeutic, Preventative Strategies for Reducing Cardiovascular Risk in Primary Prevention-A Cohort Study
}

\author{
Małgorzata Chlabicz ${ }^{1,2}$ D , Jacek Jamiołkowski ${ }^{1}$, Wojciech Łaguna ${ }^{3}$, Marlena Dubatówka ${ }^{1}$ (D), Paweł Sowa ${ }^{1}$ (D), \\ Magda Łapińska ${ }^{1}$, Anna Szpakowicz ${ }^{4}$, Natalia Zieleniewska ${ }^{1}$, Magdalena Zalewska ${ }^{1}$ (D), Andrzej Raczkowski ${ }^{1}$ \\ and Karol A. Kamiński 1,4,*(D)
}

check for updates

Citation: Chlabicz, M.; Jamiołkowski, J.; Łaguna, W.; Dubatówka, M.; Sowa,

P.; Łapińska, M.; Szpakowicz, A.;

Zieleniewska, N.; Zalewska, M.;

Raczkowski, A.; et al. Effectiveness of Lifestyle Modification vs.

Therapeutic, Preventative Strategies for Reducing Cardiovascular Risk in Primary Prevention-A Cohort Study. J. Clin. Med. 2022, 11, 688. https:// doi.org/10.3390/jcm11030688

Academic Editors: Arrigo Cicero and Francesco Giallauria

Received: 30 December 2021

Accepted: 26 January 2022

Published: 28 January 2022

Publisher's Note: MDPI stays neutral with regard to jurisdictional claims in published maps and institutional affiliations.

Copyright: (C) 2022 by the authors. Licensee MDPI, Basel, Switzerland. This article is an open access article distributed under the terms and conditions of the Creative Commons Attribution (CC BY) license (https:// creativecommons.org/licenses/by/ $4.0 /)$.
1 Department of Population Medicine and Lifestyle Diseases Prevention, Medical University of Białystok, 15-259 Białystok, Poland; mchlabicz@op.pl (M.C.); jacek909@wp.pl (J.J.); marlena.dubatowka@umb.edu.pl (M.D.); mailtosowa@gmail.com (P.S.); magda.lapinska@umb.edu.pl (M.Ł.); drobeknatalia@gmail.com (N.Z.); mzalewska@o2.pl (M.Z.); andrzej.raczkowski@umb.edu.pl (A.R.)

2 Department of Invasive Cardiology, Medical University of Białystok, 15-259 Białystok, Poland

3 Faculty of Computer Science, Bialystok University of Technology, 15-259 Białystok, Poland; wojciech.laguna@gmai.com

4 Department of Cardiology, Medical University of Białystok, 15-259 Białystok, Poland; akodi@poczta.onet.pl

* Correspondence: fizklin@wp.pl; Tel.: +48-856-865-371

\begin{abstract}
Background: Cardiovascular diseases (CVD) are still the leading cause of death in developed countries. The aim of this study was to calculate the potential for CV risk reduction when using three different prevention strategies to evaluate the effect of primary prevention. Methods: A total of 931 individuals aged 20-79 years old from the Bialystok PLUS Study were analyzed. The study population was divided into CV risk classes. The Systematic Coronary Risk Estimation (SCORE), Framingham Risk Score (FRS), and LIFE-CVD were used to assess CV risk. The optimal prevention strategy assumed the attainment of therapeutic goals according to the European guidelines. The moderate strategy assumed therapeutic goals in participants with increased risk factors: a reduction in systolic blood pressure by $10 \mathrm{mmHg}$ when it was above $140 \mathrm{mmHg}$, a reduction in total cholesterol by $25 \%$ when it was above $190 \mathrm{mg} / \mathrm{dL}$, and a reduction in body mass index below 30 . The minimal prevention strategy assumed that $\mathrm{CV}$ risk would be lowered by lifestyle modifications. The greatest $\mathrm{CV}$ risk reduction was achieved in the optimal model and then in the minimal model, and the lowest risk reduction was achieved in the moderate model, e.g., using the optimal model of prevention (Model 1). In the total population, we achieved a reduction of $-1.74 \%$ in the 10 -year risk of CVD death (SCORE) in relation to the baseline model, a $-0.85 \%$ reduction when using the moderate prevention model (Model 2), and a $-1.11 \%$ reduction when using the minimal prevention model (Model 3). However, in the low CV risk class, the best model was the minimal one (risk reduction of $-0.72 \%$ ), which showed even better results than the optimal one (reduction of $-0.69 \%$ ) using the FRS. Conclusion: A strategy based on lifestyle modifications in a population without established CVD could be more effective than the moderate strategy used in the present study. Moreover, applying a minimal strategy to the low CV risk class population may even be beneficial for an optimal model.
\end{abstract}

Keywords: cardiovascular risk; lifestyle modification; population studies

\section{Introduction}

Cardiovascular diseases (CVD) are still the leading diseases in the European population [1] despite the fact that we have guidelines for CVD prevention, lifestyle, and the management of risk factors [2,3]. The latest European primary prevention survey showed that a large number of individuals with high CVD risk have inadequate control of lipids, blood pressure (BP), and diabetes and maintain unhealthy lifestyles [4]. Furthermore, 
multiple European reports of secondary prevention have revealed that a large number of patients with CVD maintain unhealthy lifestyles in terms of their diet, smoking, and sedentary behavior and that they did not achieve their low-density lipoprotein cholesterol (LDL-C), BP, and glucose targets [5,6]. Thus, it is imperative to reduce CVD risk by improving preventive programs.

Many studies show that a healthy lifestyle and the control of disorders such as hypertension $(\mathrm{AH})$, hypercholesterolemia, and excess body weight prevent CVD events. Nevertheless, many of these disorders may go undiagnosed and therefore untreated. Accordingly, special attention should be given to those without a CVD diagnosis and who are at increased risk of CVD who consider themselves healthy and who may be reluctant to undergo diagnostic and therapeutic procedures. Therefore, in this study, we focused on assessing CV risk in people without a known CVD, most of whom were unaware of their increased CV risk. For this purpose, we used various validated calculators to assess CV risk in primary prevention $[7,8]$. The Systematic Coronary Risk Estimation-Polish version (Pol-SCORE) was used to assess the 10-year risk of fatal CV based on the following risk factors: age, gender, smoking, systolic blood pressure (BPs), and total cholesterol (TC) for individuals aged 40-70 [9,10]. The Framingham Risk Score (FRS) was used to predict the 10-year risk of developing the first CVD event (coronary death, myocardial infarction (MI), coronary insufficiency, angina, ischemic stroke, hemorrhagic stroke, transient ischemic attack, peripheral artery disease, or heart failure) using scores for lipids or body mass index (BMI) based on the following factors: age, diabetes, smoking, treated and untreated BPs, TC, high-density lipoprotein cholesterol (HDL-c), or BMI-replacing lipids [11]. The lifetime-perspective model for individualizing cardiovascular disease prevention strategies in apparently healthy people (LIFE-CVD) estimates the probability of survival free of heart attack or stroke; a 10-year risk of MI, stroke, or CV death; and a lifetime risk of MI, stroke, or $\mathrm{CV}$ death using the following factors: age, gender, smoking, geographic region, diabetes, parental history of MI prior to age 60, BPs, BMI, TC, HDL-c, and low-density lipoprotein cholesterol (LDL-c) [12].

We designed three different prevention models. In the optimal model (therapeutic prevention strategy (Model 1)), we ideally assumed the attainment of therapeutic goals in patients with present CV risk factors: successful BPs reduction below $130 \mathrm{mmHg}$; LDL-C reduction below $116 \mathrm{mg} / \mathrm{dL}(3.0 \mathrm{mmol} / \mathrm{L})$ in the low CV risk class, below $100 \mathrm{mg} / \mathrm{dL}$ $(2.6 \mathrm{mmol} / \mathrm{L})$ in the moderate $\mathrm{CV}$ risk class, below $70 \mathrm{mg} / \mathrm{dL}(1.8 \mathrm{mmol} / \mathrm{L})$ in the high $\mathrm{CV}$ risk class, and below $55 \mathrm{mg} / \mathrm{dL}(1.4 \mathrm{mmol} / \mathrm{L})$ in the very high CV risk class; TC level reduction below $156 \mathrm{mg} / \mathrm{dL}(4.0 \mathrm{mmol} / \mathrm{L})$; BMI reduction below 25; and smoking cessation. In the moderate therapeutic prevention strategy (Model 2), we assumed more realistic therapeutic goals: successful BPs lowering by $10 \mathrm{mmHg}$ when over $140 \mathrm{mmHg}$; LDL-C reduction by $25 \%$ when over $116 \mathrm{mg} / \mathrm{dL}(3.0 \mathrm{mmol} / \mathrm{L})$ in the low $\mathrm{CV}$ risk class, over $100 \mathrm{mg} / \mathrm{dL}(2.6 \mathrm{mmol} / \mathrm{L})$ in the moderate CV risk class, over $70 \mathrm{mg} / \mathrm{dL}(1.8 \mathrm{mmol} / \mathrm{L})$ in the high $\mathrm{CV}$ risk class, and over $55 \mathrm{mg} / \mathrm{dL}(1.4 \mathrm{mmol} / \mathrm{L})$ in the very high $\mathrm{CV}$ risk class; TC level reduction by 25\% when over $190 \mathrm{mg} / \mathrm{dL}(4.9 \mathrm{mmol} / \mathrm{L})$; and BMI reduction to below 30. In the minimal prevention strategy (a population-based approach (Model 3)), we assumed risk factors modifications that are attainable via lifestyle modifications, namely the lowering the following values in the analyzed population: TC and LDL-C levels by $10 \%$, BPs by $5 \mathrm{mmHg}$, and BMI by $5 \%$, accompanied by smoking cessation.

The aim of this study was to calculate the potential for CV risk reduction using the three different prevention strategies outlined above to evaluate the effect of primary prevention using validated and well-known scales across a total population as well as by $\mathrm{CV}$ risk categories.

Calculating risk reduction by using different degrees of prevention intensity can help local authorities to improve their prevention programs. The use of real-time CV risk data is a powerful factor for the optimization of evidence-based policy. This data-driven approach can enable responsible people to choose the right health strategies that can lead to better health for all. 


\section{Materials and Methods}

The Bialystok PLUS Study was conducted in 2017-2020 on a sample of Bialystok residents aged 20-79 years old. Bialystok is a city in the eastern part of Poland and has a population of 297,500 inhabitants.

\subsection{Recruitment of Bialystok PLUS Study Participants}

Each year (in the middle of the year, after June 30th, when demography statistics by the Main Statistical Office in Poland are calculated), we received a pseudonymized list of Bialystok citizens from the Municipal Office in Bialystok. The dataset was limited to people aged 20-79 years old, and categories based on gender and 5-year intervals (20-24, 25-29, etc.) were assigned, providing a total of 24 subcategories. We randomly sampled citizens from each subcategory separately, in such a number that allowed us to obtain a similar proportion distribution similar to that in the city's population. After sampling, the identifiers of the selected citizens were sent back to the Municipal Office, and we received their names and addresses in order to contact them. The sampled citizens were invited to participate in the study through a letter and were encouraged to contact us by phone or email to schedule a visit. We sent second and even third invitation letters after a period of time for those who did not respond. We randomly sampled a number of citizens to be examined for the next year. There were no exclusion criteria; however, for pregnant women, some examinations were not carried out in certain subpopulations (e.g., OGTT in diabetics).

\subsection{Data Collection}

Data collection was conducted by trained research staff. At the time of study entry, a detailed medical history was collected from each patient using questionnaires. The comprehensive assessment was performed as described previously [7].

\subsection{Ethical Issues}

Ethical approval for this study was provided by the Ethics Committee of the Medical University of Bialystok (Poland) on 31 March 2016 (approval number: R-I-002/108/2016). The study was conducted in accordance with the Declaration of Helsinki, and all participants gave written informed consent.

\subsection{Division into CV Risk Classes}

According to the "2019 ESC/EAS guidelines for the management of dyslipidemias: lipid modification to reduce cardiovascular risk" [2] recommendations, the study population was divided into $\mathrm{CV}$ risk classes. A detailed description of the subdivision is presented elsewhere [8].

\subsection{Designed Prevention Models}

We designed three different prevention models, all of which are described above and are shown in Figure 1.

\subsection{Calculators for the Assessment of CV Risk in Primary Prevention}

The Systematic Coronary Risk Estimation (SCORE) was calculated, participants who were pre-qualified in the high and very high CV risk classes according to the aforementioned recommendations were excluded [2]. We used the Pol-SCORE system because it was recalibrated in Poland $[9,10]$. According to the original risk stratification in the ESC guidelines, participants with previously diagnosed CVD (myocardial infarction-MI, ischemic heart disease-IHD, stroke, transient ischemic attack-TIA, peripheral arterial disease-PAD, significant plaque on carotid ultrasound $>50 \%$ ), previously diagnosed DM or DM diagnosed at the time of study entry, moderate or severe chronic kidney diseases (CKD) at the time of study entry, markedly elevated single risk factor (TC $>310 \mathrm{mg} / \mathrm{dL}$, LDL-c $>190 \mathrm{mg} / \mathrm{dL}, \mathrm{BP} \geq 180 / 110 \mathrm{mmHg}$ ) at the time of study entry, and individuals aged 
younger than 40 years old or older than 70 years old were excluded from the Pol-SCORE calculation, as they present a higher $\mathrm{CV}$ risk than that calculated according to the algorithm.
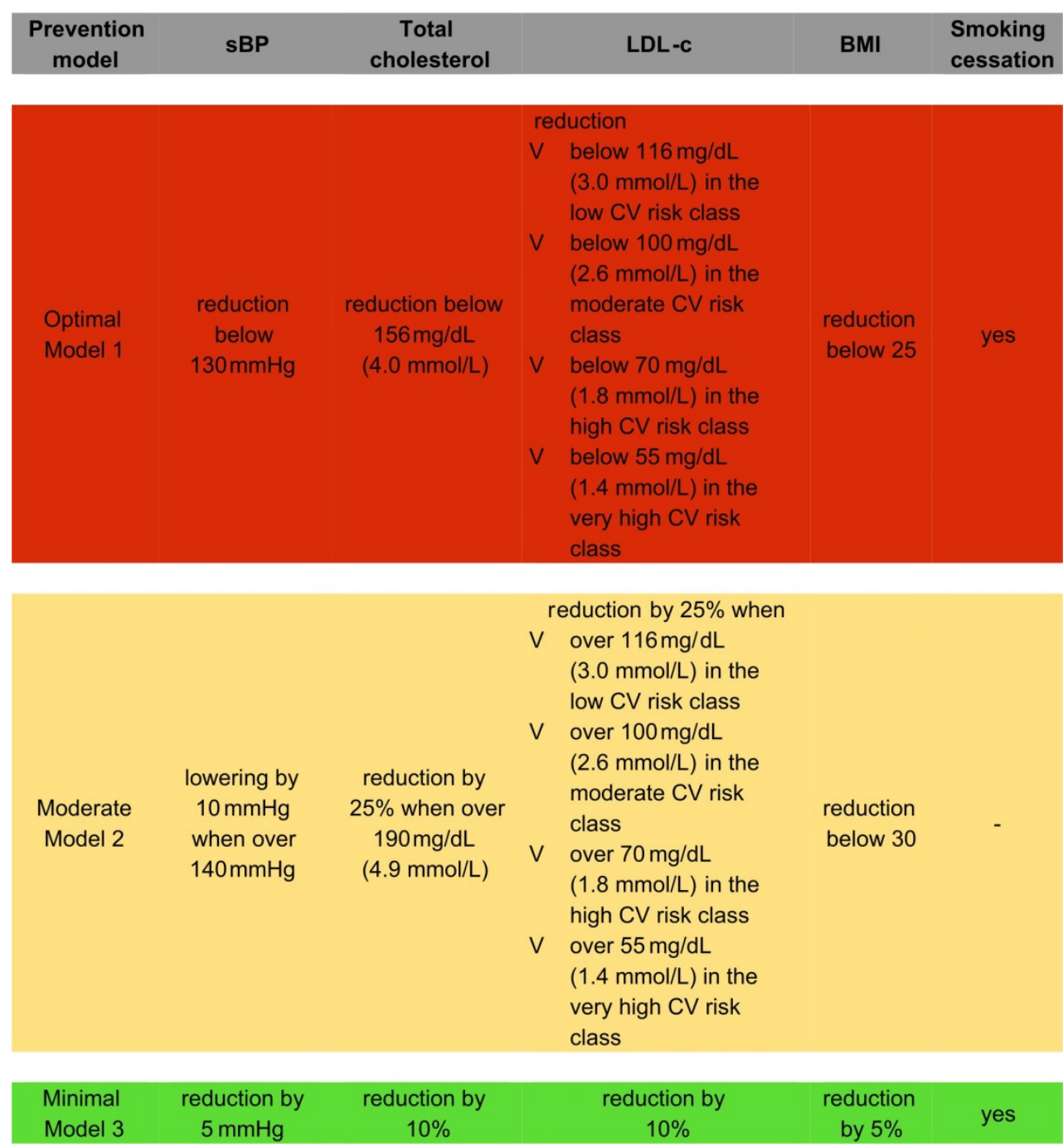

Figure 1. Prevention models designed.

The Cardiovascular Disease Framingham Heart Study (FRS) predicted a 10-year risk of developing the first CVD event (coronary heart disease, stroke, peripheral artery disease, or heart failure) using scores for BMI or lipids based on the following factors: age, smoking, diabetes, treated and untreated BPs, TC, high-density lipoprotein cholesterol (HDL-C), or lipids replacing BMI [11]. Participants with previously diagnosed CVD (myocardial infarction-MI, ischemic heart disease-IHD, stroke, transient ischemic attack-TIA, peripheral arterial disease-PAD, significant plaque on carotid ultrasound $>50 \%$ ) and those who were younger than 30 years old or older than 74 years old were excluded from further analysis.

To assess lifetime risk, the LIFE-CVD was used. This model calculates a 10-year risk of myocardial infarction (MI), stroke, or CV death; lifetime risk of MI, stroke, or CV death; or the probability of survival-free heart attack or stroke using the following factors: age, gender, smoking, geographic region, diabetes, parental history of MI prior to age 60, BPs, BMI, TC, HDL-C, and LDL-C [12]. Participants with previously diagnosed CVD (MI, IHD, stroke, TIA, peripheral arterial disease, significant plaque on carotid ultrasound $>50 \%$ ), and who were younger than 45 years old or older than 79 years old were excluded from this analysis. 
Patients in whom a certain risk assessment method could not be applied were excluded only from the analysis based on that particular method. Basic CV risk and the CV risk in the assumed models were estimated according to the Pol-SCORE [9], FRS [11], and LIFE-CVD [12,13] calculators. All of the analyses were also performed in the investigated population, which was divided according to CV risk classes using the latest 2019 ESC/EAS guidelines [2], with 931 people being included in the analyzed sample. A total of 560 met the age requirement, and 465 satisfied of the Pol-SCORE calculation conditions [9]. Predicting the 10-year risk for the development of the first CVD event using FRS scores, we analyzed 830 people from the sample who met the age requirements [11]. Overall, 721 people from the sample had sufficient data and satisfied all of the conditions [11] for Framingham lipid and BMI-based model calculation. To estimate the risk of the first CVD event within 10 years and over one's lifetime (LIFE-CVD), we analyzed 531 people from the sample who met the age requirements, and 469 satisfied all of the conditions for LIFE-CVD calculation [12,13].

\subsection{The Estimation of the Number of the Local Inhabitants}

Estimations of the number of the local inhabitants who may die (Pol-SCORE) due to CVD within 10 years; who may develop their first CVD event within 10 years (FRS); or who may develop their first MI, stroke, or CV death within 10 years and within their lifetime (LIFE-CVD) were also performed. The scores that were used to estimate the risk are only applicable to primary prevention, that is, in people without previously diagnosed CVD. We obtained the frequency of CVD in our study population (931 participants), and based on this, we calculated the prevalence of CVD in the total population of the city using 5-year strata separately in the male and female participants. In 2018, the local population aged 20-79 years was equal to 208,303: 112,545 females and 95,758 males. After applying the aforementioned conversion method, using the 5-year strata, it was estimated that there were 196,184 inhabitants without CVD in the age group reflected in our study.

Applying the age criterion on the population $(40 \leq$ age $\leq 70)$ resulted in 104,998 people being able to participate. Calculating the Pol-SCORE risk for each person in the sample allowed us to estimate the number of people from the total population who would survive within 10 years after applying a particular prevention strategy. The expected number of deceased individuals was estimated based on the binomial distribution, where each person from the sample represented people from the population in the same age-gender category. We grouped the sample and population into age-gender categories, where each category contained people of the same gender arranged in five-year intervals.

The estimation of the number of people who would not develop their first CVD event (coronary heart disease, stroke, peripheral artery disease, or heart failure) within 10 years (FRS) was determined after applying a particular prevention strategy and applying the Framingham age criterion on the local population $(30 \leq$ age $\leq 74)$ and resulted in 158,183 people. Calculating the Framingham risk for each group allowed us to calculate the number of people who not develop their first CVD event within 10 years after applying prevention strategies. We grouped the sample and population into age-gender categories, with each category containing people of the same gender arranged in five-year intervals.

Applying the age criterion for LIFE-CVD on the local population (45 $\leq$ age $\leq 79$ ) resulted in 98,086 people. Calculating the LIVE-CVD 10-year and lifetime risk for each person in the sample allowed us to estimate the number of people from the population who would not develop their first CVD event within 10 years or in their lifetime after the application of a particular prevention strategy. The expected number of deceased was estimated based on the binomial distribution, where each person from the sample represents people from the population in the same age-gender category. We grouped the sample and population into age-gender categories, with each category containing people of the same gender arranged in five-year intervals. 


\subsection{Statistical Analysis}

Descriptive statistics for the quantitative variables were presented as means and 95\% confidence intervals (95\% CI) and as the counts and frequencies for the qualitative variables. The IBM SPSS Statistics 27.0 statistical software (Armonk, NY, USA) was used for all of the calculations.

\section{Results}

A total of 2449 residents were randomly selected from the mayor's office database and were invited to participate in the study. A total of 966 residents responded and were examined (Figure 2). Due to incomplete data, 35 people were excluded from further analysis. Overall, 931 individuals were included in the research group, out of which 63 (6.8\%) participants had established CVD, $275(29.6 \%)$ had a history of $\mathrm{AH}, 71(7.6 \%)$ had a history of diabetes mellitus (DM), and 186 (20.1\%) smoked cigarettes.

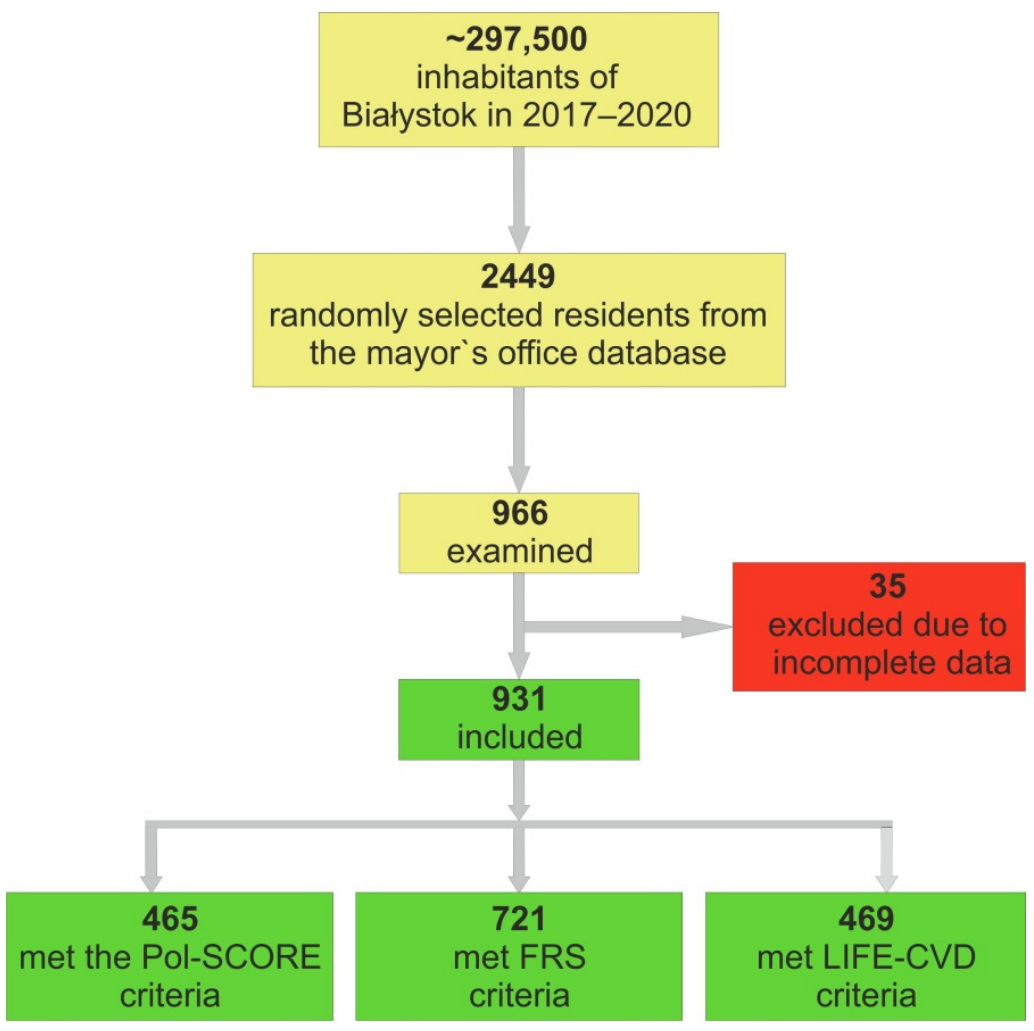

Figure 2. Analyzed cohort of included individuals.

The mean age of the study population was $49.1 \pm 15.5$ years old, and $43.2 \%$ of the participants were male. The characteristics of the study population are presented in Table 1 , and detailed data are elsewhere [8]. In 2018, the local population aged 20-79 years old from which we sampled was equal to 208,303 . The mean age of this local population, according to the 2018 Central Statistical Office data, was $47.4 \pm 15.8$ years old, and $46.0 \%$ of the participants were male. 
Table 1. The baseline characteristics of the analyzed population.

\begin{tabular}{|c|c|}
\hline Variable & $\begin{array}{l}\text { Total Population } \\
\qquad n=931\end{array}$ \\
\hline Age, years & $49.1 \pm 15.5$ \\
\hline Male sex, $n$ & $402(43.2)$ \\
\hline BPs, mmHg & $124.4 \pm 17.7$ \\
\hline $\mathrm{BPd}, \mathrm{mmHg}$ & $81.7 \pm 10.1$ \\
\hline $\mathrm{BP} \geq 140$ and $/$ or $\geq 90 \mathrm{mmHg}$ & $253(27.2)$ \\
\hline HR, bpm & $72.3 \pm 10.9$ \\
\hline Fasting glucose, $\mathrm{mg} / \mathrm{dL}$ & $102.1 \pm 21.0$ \\
\hline OGTT 120 min glucose, mg/dL & $124.3 \pm 39.7$ \\
\hline $\mathrm{HbA1c}, \%$ & $5.5 \pm 0.7$ \\
\hline $\mathrm{TC}, \mathrm{mg} / \mathrm{dL}$ & $192.5 \pm 40.8$ \\
\hline LDL-C, mg/dL & $124.4 \pm 37.8$ \\
\hline HDL-C, mg/dL & $62.6 \pm 17.3$ \\
\hline $\mathrm{TG}, \mathrm{mg} / \mathrm{dL}$ & $113.2 \pm 77.6$ \\
\hline hs-CRP, mg/l & $1.7 \pm 4.2$ \\
\hline Creatinine, $\mu \mathrm{mol} / \mathrm{L}$ & $70.9 \pm 14.9$ \\
\hline $\mathrm{CrCl}, \mathrm{mL} / \mathrm{min}$ & $115.0 \pm 40.7$ \\
\hline LVEF Biplane, $\%$ & $58.5 \pm 5.7$ \\
\hline BMI, $\mathrm{kg} / \mathrm{m}^{2}$ & $26.8 \pm 5.0$ \\
\hline $\mathrm{BMI}<25 \mathrm{~kg} / \mathrm{m}^{2}$ & $330(35.4)$ \\
\hline BMI $25-29.99 \mathrm{~kg} / \mathrm{m}^{2}$ & $352(37.8)$ \\
\hline $\mathrm{BMI} \geq 30 \mathrm{~kg} / \mathrm{m}^{2}$ & $249(26.7)$ \\
\hline History of hypertension & $275(29.6)$ \\
\hline Undiagnosed hypertension * & $107(11.5)$ \\
\hline History of hypercholesterolemia & $290(31.1)$ \\
\hline Undiagnosed hypercholesterolemia ** & 399 (42.9) \\
\hline History of diabetes & $71(7.6)$ \\
\hline Undiagnosed diabetes $* * *$ & $57(6.1)$ \\
\hline Currently smoking & $186(20.1)$ \\
\hline
\end{tabular}

Data are shown as $n(\%)$ and mean \pm SD. BP: blood pressure; BPd: diastolic blood pressure; BPs: systolic blood pressure; bpm: beats per minute; $\mathrm{CrCl}$ : creatinine clearance using Cockcroft-Gault equation; $\mathrm{HbA1c}$ : hemoglobin A1c; HDL-C: high-density lipoprotein; HR: heart rate; hs-CRP; high-sensitivity C-reactive protein; kg: kilogram; LDL-C: low-density lipoprotein; $\mathrm{mmHg}$, millimeters of mercury; LVEF Biplane: left ventricular ejection fraction biplane Simpson's method; OGTT: oral glucose tolerance test; SD: standard deviation; TC: total cholesterol; TG: triglycerides. ${ }^{*} \mathrm{BPs} \geq 140$ and/or BPd $\geq 90 \mathrm{mmHg}$. ${ }^{* *} \mathrm{TC}>190 \mathrm{mg} / \mathrm{dL}$ or LDL-c $>116 \mathrm{mg} / \mathrm{dL}$ in low CV class, $>100 \mathrm{mg} / \mathrm{dL}$ in moderate CV class, $>70 \mathrm{mg} / \mathrm{dL}$ in high CV class, and $>55 \mathrm{mg} / \mathrm{dL}$ in very high CV class. ${ }^{* *}$ Fasting glucose $\geq 126 \mathrm{mg} / \mathrm{dL}$ or OGGT $120 \mathrm{~min}$ glucose $\geq 200 \mathrm{mg} / \mathrm{dL}$.

The percentages of the very high risk, high risk, moderate risk, and low CV risk classes were $17.6 \%, 13.5 \%, 22.8 \%$, and $46.1 \%$, respectively [8]. The mean Pol-SCORE risk was $3.98 \%(95 \%$ CI 3.54, 4.42), the mean FRS-Lipids was $8.42 \%(95 \%$ CI 7.82, 9.02), and the mean FRS-BMI was 10.73\% (95\% CI 10.03, 11.43). The mean LIFE-CVD 10-year risk and LIFE-CVD lifetime risk were 4.88\% (95\% CI 4.53, 5.24) and 17.31\% (95\% CI 16.56, 18.07), respectively. Detailed baseline data for the CV risk classes are presented in Table 2. 
Table 2. Prediction of 10-year risk of fatal CVD (Pol-SCORE), 10-year risk of developing first CVD event (Framingham Cardiovascular Disease), and 10-year risk or life risk of MI, stroke, or CV death (lifetime-perspective model for individualizing cardiovascular disease prevention strategies in apparently healthy people: LIFE-CVD).

\begin{tabular}{|c|c|c|c|c|}
\hline $\begin{array}{l}\text { Prevention } \\
\text { Strategy }\end{array}$ & Scales & $\begin{array}{l}\text { CV Risk } \\
\text { Classes }\end{array}$ & $n$ & $\begin{array}{l}\text { Average Risk (\%) } \\
\text { Mean (95\% CI) }\end{array}$ \\
\hline \multirow{25}{*}{ Baseline } & \multirow{5}{*}{ Pol-SCORE } & Low & 126 & $0.51(0.47-0.55)$ \\
\hline & & Moderate & 201 & $2.50(2.35-2.65)$ \\
\hline & & High & 90 & $6.10(5.62-6.58)$ \\
\hline & & Very high & 48 & $15.29(13.60-16.98)$ \\
\hline & & Total & 465 & $3.98(3.54-4.42)$ \\
\hline & \multirow{5}{*}{ FRS_Lipids } & Low & 319 & $2.40(2.22-2.58)$ \\
\hline & & Moderate & 205 & 8.55 (7.94-9.16) \\
\hline & & High & 113 & $13.18(12.08-14.28)$ \\
\hline & & Very high & 84 & $24.53(23.10-25.96)$ \\
\hline & & Total & 721 & $8.42(7.82-9.02)$ \\
\hline & \multirow{5}{*}{ FRS-BMI } & Low & 319 & $3.15(2.91-3.39)$ \\
\hline & & Moderate & 205 & $11.84(11.02-12.66)$ \\
\hline & & High & 113 & $17.59(16.06-19.12)$ \\
\hline & & Very high & 84 & $27.54(26.55-28.53)$ \\
\hline & & Total & 721 & $10.73(10.03-11.43)$ \\
\hline & \multirow{5}{*}{$\begin{array}{l}\text { LIFE-CVD } \\
\text { 10-year risk }\end{array}$} & Low & 70 & $1.32(1.16-1.48)$ \\
\hline & & Moderate & 182 & $3.24(3.04-3.44)$ \\
\hline & & High & 114 & $4.98(4.68-5.29)$ \\
\hline & & Very high & 103 & 10.09 (9.17-11.01) \\
\hline & & Total & 469 & $4.88(4.53-5.24)$ \\
\hline & \multirow{5}{*}{$\begin{array}{l}\text { LIFE-CVD } \\
\text { lifetime risk }\end{array}$} & Low & 70 & $11.46(10.66-12.27)$ \\
\hline & & Moderate & 182 & $16.42(15.45-17.39)$ \\
\hline & & High & 114 & $17.76(16.22-19.30)$ \\
\hline & & Very high & 103 & $22.37(20.40-24.34)$ \\
\hline & & Total & 469 & $17.31(16.56-18.07)$ \\
\hline
\end{tabular}

The data are shown as the means and 95\% confidence interval (95\% CI). BMI, body mass index; CV, cardiovascular; CVD, cardiovascular disease FRS, Cardiovascular Disease Framingham Heart Study; LIFE-CVD, lifetimeperspective model for individualizing cardiovascular disease prevention strategies in apparently healthy people; SCORE, Systematic Coronary Risk Estimation.

Using the optimal prevention model (Model 1), we can achieve a reduction of $-1.74 \%$ $(95 \%$ CI $-1.46,-2.02)$ in the 10-year risk of CVD death (Pol-SCORE) in relation to the baseline model in the total population, a $-0.85 \%(95 \% \mathrm{CI}-0.72,-0.98)$ reduction approaching that of the moderate model of prevention (Model 2) and a $-1.11 \%(95 \% \mathrm{CI}-0.92,-1.30)$ reduction approaching that of the minimal model of prevention (Model 3). The 10-year risk of developing the first CVD event calculated with the FRS using the lipid model included a reduction of $-3.28 \%$ (95\% CI -2.97, -3.59) when using prevention model 1, $-1.54 \%$ (95\% CI - 1.38, -1.70$)$ when using prevention model 2 , and $-2.04 \%$ (95\% CI $-1.85,-2.23)$ when using prevention model 3 in the total population. Using the FRS based on BMI, we were able to predict risk reductions of $-2.42 \%(95 \% \mathrm{CI}-2.15,-2.69),-0.42 \%(95 \% \mathrm{CI}-0.35,-0.49)$, and $-1.74 \%$ $(95 \%$ CI $-1.54,-1.94)$ when using prevention models 1, 2, and 3, respectively. Similar results were found in the moderate, high, and very high CV risk categories. However, in 
the low $\mathrm{CV}$ risk class, the best model was the minimal model (risk reduction of $-0.72 \%$ (95\% CI $-0.60,-0.84)$ ), which showed even better performance than the optimal one (reduction of $-0.69 \%(95 \% \mathrm{CI}-0.55,-0.83))$ using the FRS-BMI. Detailed data for the CV risk classes are presented in Table 3. Using the LIFE-CVD model in the optimal prevention strategy, the probability of survival-free heart attack or stroke increased by 2.01 $(95 \%$ CI $1.85,2.17)$ life years, and the reduction in the lifetime risk of $\mathrm{MI}$, stroke, or CV death in the total population was $-7.12 \%(95 \% \mathrm{CI}-6.47,-7.78)$. In the moderate prevention strategy, the probability of survival-free of heart attack or stroke increased by 0.83 $(95 \%$ CI $0.77,0.90)$ life years; there was a $-3.75 \%(95 \%$ CI $-3.46,-4.05)$ reduction in the lifetime risk of $\mathrm{MI}$, stroke, or $\mathrm{CV}$ death in the total population. In the minimal prevention strategy, the probability of survival free of heart attack or stroke increased by 1.21 $(95 \%$ CI 1.10, 1.32) life years; there was a $-3.49 \%(95 \%$ CI $-3.29,-3.69)$ reduction in the lifetime risk of $\mathrm{MI}$, stroke, or CV death in the total population. What is particularly salient in this analysis is a higher probability of survival years free of heart attack or stroke in the low CV risk category with the use of the minimal strategy $(1.06$ (95\% CI 0.80, 1.32) life years) compared to the moderate $(0.59(95 \%$ CI $0.47,0.72)$ life year) and even the optimal strategy $(0.97(95 \%$ CI $0.68,1.27)$ life years) (Figure 2 Panel D). However, when using the minimal strategy, we were able to achieve a long-term CV risk reduction in LIFE-CVD of $-2.21 \%(95 \% \mathrm{CI}-1.96,-2.45)$; using the moderate models, we were able to achieve a $-1.63 \%(95 \% \mathrm{CI}-1.31,-1.95)$ reduction, and when using the optimal model, $\mathrm{a}-1.76 \%$ $(95 \%$ CI $-1.34,-2.17)$ reduction was able to be achieved. We obtained similar results by lowering the LIFE-CVD 10-year risk and LIFE-CVD lifetime risk of MI, stroke, and CV death in the low CV class. Using the optimal model of prevention, the calculated risk decreased by $-0.23 \%(95 \%$ CI $-0.17,-0.30)$; using the moderate model, the CV risk decreased by $-0.20 \%(95 \% \mathrm{CI}-0.16,-0.25)$; and using the minimum model, the CV risk decreased by $-0.29 \%(95 \% \mathrm{CI}-0.24,-0.35)$ for the 10 -year risk of MI, stroke, and CV death. Detailed data for the particular CV risk classes are presented in Tables 2 and 4 and in Figure 3.

Table 3. Estimation of the effects of particular prevention models on 10-year risk of fatal CVD (Pol-SCORE); 10-year risk of developing the first CVD event (Framingham Cardiovascular Disease); and 10-year risk or life risk of MI, stroke, or CV death (lifetime-perspective model for individualizing cardiovascular disease prevention strategies in apparently healthy people LIFE-CVD) in the appropriate study population.

\begin{tabular}{|c|c|c|c|c|c|}
\hline $\begin{array}{c}\text { Prevention } \\
\text { Strategy }\end{array}$ & Scales & CV Risk Classes & $n$ & $\begin{array}{c}\text { Average Risk } \\
(\%) \\
\text { Mean (95\% CI) }\end{array}$ & $\begin{array}{c}\text { The Absolute Value of the Reduction } \\
\text { from Baseline Risk }(\%) \\
\text { Mean }(95 \% \text { CI) }\end{array}$ \\
\hline \multirow{15}{*}{$\begin{array}{l}\text { Model } 1 \\
\text { Optimal }\end{array}$} & \multirow{5}{*}{ Pol-SCORE } & Low & 126 & $0.37(0.34-0.40)$ & $-0.14(0.12-0.16)$ \\
\hline & & Moderate & 201 & $1.69(1.57-1.81)$ & $-0.81(0.71-0.91)$ \\
\hline & & High & 90 & $3.71(3.30-4.12)$ & $-2.40(2.07-2.73)$ \\
\hline & & Very high & 48 & $6.66(5.94-7.38)$ & $-8.63(7.16-10.10)$ \\
\hline & & Total & 465 & $2.24(2.03-2.45)$ & $-1.74(1.46-2.02)$ \\
\hline & \multirow{5}{*}{ FRS_Lipids } & Low & 319 & 1.59 (1.49-1.69) & $-0.82(0.71-0.93)$ \\
\hline & & Moderate & 205 & $5.42(5.03-5.81)$ & $-3.13(2.76-3.50)$ \\
\hline & & High & 113 & $7.67(6.86-8.48)$ & $-5.51(4.81-6.21)$ \\
\hline & & Very high & 84 & 14.55 (13.03-16.07) & $-9.98(8.73-11.23)$ \\
\hline & & Total & 721 & $5.14(4.75-5.53)$ & $-3.28(2.97-3.59)$ \\
\hline & \multirow{5}{*}{ FRS-BMI } & Low & 319 & $2.47(2.32-2.62)$ & $-0.69(0.55-0.83)$ \\
\hline & & Moderate & 205 & $9.03(8.43-9.63)$ & $-2.81(2.33-3.29)$ \\
\hline & & High & 113 & 13.17 (11.90-14.44) & $-4.43(3.64-5.22)$ \\
\hline & & Very high & 84 & $22.23(20.72-23.74)$ & $-5.31(4.15-6.47)$ \\
\hline & & Total & 721 & $8.31(7.74-8.88)$ & $-2.42(2.15-2.69)$ \\
\hline
\end{tabular}


Table 3. Cont

\begin{tabular}{|c|c|c|c|c|c|}
\hline $\begin{array}{c}\text { Prevention } \\
\text { Strategy }\end{array}$ & Scales & CV Risk Classes & $n$ & $\begin{array}{c}\text { Average Risk } \\
(\%) \\
\text { Mean }(95 \% \mathrm{CI})\end{array}$ & $\begin{array}{c}\text { The Absolute Value of the Reduction } \\
\text { from Baseline Risk (\%) } \\
\text { Mean }(95 \% \text { CI) }\end{array}$ \\
\hline & \multirow{5}{*}{ FRS-BMI } & Low & 319 & $2.47(2.32-2.62)$ & $-0.69(0.55-0.83)$ \\
\hline & & Moderate & 205 & $9.03(8.43-9.63)$ & $-2.81(2.33-3.29)$ \\
\hline & & High & 113 & 13.17 (11.90-14.44) & $-4.43(3.64-5.22)$ \\
\hline & & Very high & 84 & $22.23(20.72-23.74)$ & $-5.31(4.15-6.47)$ \\
\hline & & Total & 721 & $8.31(7.74-8.88)$ & $-2.42(2.15-2.69)$ \\
\hline & \multirow{5}{*}{$\begin{array}{l}\text { LIFE-CVD } \\
10 \text {-year risk }\end{array}$} & Low & 70 & $1.08(0.95-1.21)$ & $-0.23(0.17-0.30)$ \\
\hline & & Moderate & 182 & $2.28(2.13-2.43)$ & $-0.96(0.85-1.07)$ \\
\hline & & High & 114 & $2.69(2.45-2.93)$ & $-2.29(2.05-2.53)$ \\
\hline & & Very high & 103 & $3.77(3.43-4.10)$ & $-6.32(5.49-7.15)$ \\
\hline & & Total & 469 & $2.53(2.39-2.66)$ & $-2.35(2.07-2.63)$ \\
\hline & \multirow{5}{*}{$\begin{array}{l}\text { LIFE-CVD } \\
\text { lifetime risk }\end{array}$} & Low & 70 & $9.71(9.06-10.35)$ & $-1.76(1.34-2.17)$ \\
\hline & & Moderate & 182 & $11.82(11.18-12.46)$ & $-4.60(4.04-5.16)$ \\
\hline & & High & 114 & $9.25(8.66-9.84)$ & $-8.51(7.25-9.76)$ \\
\hline & & Very-high & 103 & 8.67 (8.03-9.32) & $-13.70(11.93-15.46)$ \\
\hline & & Total & 469 & $10.19(9.83-10.54)$ & $-7.12(6.47-7.78)$ \\
\hline \multirow{25}{*}{$\begin{array}{c}\text { Model } 2 \\
\text { Moderate }\end{array}$} & \multirow{5}{*}{ Pol-SCORE } & Low & 126 & $0.44(0.40-0.48)$ & $-0.07(0.06-0.08)$ \\
\hline & & Moderate & 201 & $2.12(1.98-2.26)$ & $-0.38(0.33-0.43)$ \\
\hline & & High & 90 & $4.85(4.42-5.28)$ & $-1.26(1.07-1.45)$ \\
\hline & & Very high & 48 & $11.16(9.91-12.41)$ & $-4.13(3.46-4.80)$ \\
\hline & & Total & 465 & $3.13(2.80-3.46)$ & $-0.85(0.72-0.98)$ \\
\hline & \multirow{5}{*}{ FRS—Lipids } & Low & 319 & $2.01(1.87-2.15)$ & $-0.40(0.34-0.46)$ \\
\hline & & Moderate & 205 & $6.98(6.46-7.50)$ & $-1.57(1.34-1.80)$ \\
\hline & & High & 113 & $10.24(9.33-11.15)$ & $-2.94(2.52-3.36)$ \\
\hline & & Very high & 84 & $20.57(18.99-22.15)$ & $-3.96(3.27-4.65)$ \\
\hline & & Total & 721 & $6.88(6.37-7.39)$ & $-1.54(1.38-1.70)$ \\
\hline & \multirow{5}{*}{ FRS-BMI } & Low & 319 & $3.07(2.85-3.29)$ & $-0.08(0.05-0.11)$ \\
\hline & & Moderate & 205 & $11.30(10.53-12.07)$ & $-0.54(0.38-0.70)$ \\
\hline & & High & 113 & $16.66(15.21-18.11)$ & $-0.93(0.68-1.18)$ \\
\hline & & Very high & 84 & $26.83(25.74-27.92)$ & $-0.71(0.40-1.02)$ \\
\hline & & Total & 721 & $10.31(9.64-10.98)$ & $-0.42(0.35-0.49)$ \\
\hline & \multirow{5}{*}{$\begin{array}{l}\text { LIFE-CVD } \\
10 \text {-year risk }\end{array}$} & Low & 70 & $1.11(0.99-1.24)$ & $-0.20(0.16-0.25)$ \\
\hline & & Moderate & 182 & $2.66(2.48-2.83)$ & $-0.58(0.52-0.65)$ \\
\hline & & High & 114 & $3.82(3.56-4.08)$ & $-1.16(1.05-1.28)$ \\
\hline & & Very high & 103 & $7.18(6.57-7.79)$ & $-2.91(2.54-3.27)$ \\
\hline & & Total & 469 & $3.70(3.46-3.95)$ & $-1.18(1.05-1.30)$ \\
\hline & \multirow{5}{*}{$\begin{array}{l}\text { LIFE-CVD } \\
\text { lifetime risk }\end{array}$} & Low & 70 & $9.83(9.21-10.45)$ & $-1.63(1.31-1.95)$ \\
\hline & & Moderate & 182 & $13.50(12.77-14.23)$ & $-2.92(2.59-3.26)$ \\
\hline & & High & 114 & $13.48(12.51-14.46)$ & $-4.27(3.64-4.90)$ \\
\hline & & Very high & 103 & $16.28(14.98-17.58)$ & $-6.09(5.32-6.86)$ \\
\hline & & Total & 469 & $13.56(13.05-14.06)$ & $-3.75(3.46-4.05)$ \\
\hline
\end{tabular}


Table 3. Cont.

\begin{tabular}{|c|c|c|c|c|c|}
\hline $\begin{array}{l}\text { Prevention } \\
\text { Strategy }\end{array}$ & Scales & CV Risk Classes & $n$ & $\begin{array}{c}\text { Average Risk } \\
(\%) \\
\text { Mean }(95 \% \mathrm{CI})\end{array}$ & $\begin{array}{c}\text { The Absolute Value of the Reduction } \\
\text { from Baseline Risk (\%) } \\
\text { Mean }(95 \% \text { CI) }\end{array}$ \\
\hline \multirow{25}{*}{$\begin{array}{l}\text { Model } 3 \\
\text { Minimal }\end{array}$} & \multirow{5}{*}{ Pol-SCORE } & Low & 126 & $0.38(0.35-0.41)$ & $-0.13(0.11-0.15)$ \\
\hline & & Moderate & 201 & $1.87(1.74-2.00)$ & $-0.63(0.55-0.71)$ \\
\hline & & High & 90 & $4.60(4.17-5.03)$ & $-1.50(1.25-1.75)$ \\
\hline & & Very high & 48 & $10.28(9.20-11.36)$ & $-5.01(3.71-6.31)$ \\
\hline & & Total & 465 & $2.87(2.57-3.17)$ & $-1.11(0.92-1.30)$ \\
\hline & \multirow{5}{*}{ FRS_Lipids } & Low & 319 & $1.69(1.56-1.82)$ & $-0.71(0.62-0.80)$ \\
\hline & & Moderate & 205 & $6.29(5.82-6.76)$ & $-2.26(1.98-2.54)$ \\
\hline & & High & 113 & $9.84(8.91-10.77)$ & $-3.34(2.86-3.82)$ \\
\hline & & Very high & 84 & $19.71(18.09-21.33)$ & $-4.82(3.83-5.81)$ \\
\hline & & Total & 721 & $6.38(5.88-6.88)$ & $-2.04(1.85-2.23)$ \\
\hline & \multirow{5}{*}{ FRS-BMI } & Low & 319 & $2.43(2.26-2.60)$ & $-0.72(0.60-0.84)$ \\
\hline & & Moderate & 205 & $9.51(8.81-10.21)$ & $-2.33(1.93-2.73)$ \\
\hline & & High & 113 & $14.70(13.23-16.17)$ & $-2.89(2.25-3.53)$ \\
\hline & & Very high & 84 & $24.89(23.54-26.24)$ & $-2.64(1.74-3.54)$ \\
\hline & & Total & 721 & $8.98(8.34-9.62)$ & $-1.74(1.54-1.94)$ \\
\hline & \multirow{5}{*}{$\begin{array}{l}\text { LIFE-CVD } \\
10 \text {-year risk }\end{array}$} & Low & 70 & $1.03(0.90-1.15)$ & $-0.29(0.24-0.35)$ \\
\hline & & Moderate & 182 & $2.48(2.32-2.64)$ & $-0.76(0.68-0.85)$ \\
\hline & & High & 114 & $3.81(3.56-4.06)$ & $-1.17(1.02-1.33)$ \\
\hline & & Very high & 103 & $7.64(6.82-8.46)$ & $-2.45(2.15-2.75)$ \\
\hline & & Total & 469 & $3.71(3.42-3.99)$ & $-1.16(1.05-1.26)$ \\
\hline & \multirow{5}{*}{$\begin{array}{l}\text { LIFE-CVD } \\
\text { lifetime risk }\end{array}$} & Low & 70 & $9.26(8.54-9.97)$ & $-2.21(1.96-2.45)$ \\
\hline & & Moderate & 182 & $13.19(12.33-14.06)$ & $-3.23(2.98-3.47)$ \\
\hline & & High & 114 & $14.12(12.81-15.43)$ & $-3.64(3.20-4.07)$ \\
\hline & & Very high & 103 & $17.65(15.91-19.40)$ & $-4.72(4.17-5.26)$ \\
\hline & & Total & 469 & $13.79(13.14-14.44)$ & $-3.49(3.29-3.69)$ \\
\hline
\end{tabular}

The data are shown as means and 95\% confidence intervals (95\% CI). MI, myocardial infarction; BMI, body mass index; BPs, systolic blood pressure; CV, cardiovascular; CVD, cardiovascular disease; FRS, Cardiovascular Disease Framingham Heart Study; LIFE-CVD, lifetime-perspective model for individualizing cardiovascular disease prevention strategies in apparently healthy people; SCORE, Systematic Coronary Risk Estimation; TC, total cholesterol. Model 1: optimal prevention strategy: BPs $<130 \mathrm{mmHg}, \mathrm{TC}<156 \mathrm{mg} / \mathrm{dL}, \mathrm{BMI}<25$, smoking cessation; Model 2: moderate prevention strategy: BPs lowering by $10 \mathrm{mmHg}$ when $>140 \mathrm{mmHg}$, TC lowering by $25 \%$ when $>190 \mathrm{mg} / \mathrm{dL}, \mathrm{BMI}<30$. Model 3: minimal prevention strategy: TC lowering by $10 \%$, BPs lowering by $5 \mathrm{mmHg}$, BMI lowering by $5 \%$, smoking cessation.

In Table 5, we present the estimated number of the local inhabitants who would survive (Pol-SCORE) or who would not develop their first CVD event within 10 years (FRS) and would not develop MI, stroke, or CV death (LIFE-CVD) within 10 years or within their lifetime after applying the appropriate prevention strategies. Finally, in Table 6, we present the estimated CVD burden in the local population based on an earlier analysis [8]. We performed this analysis in order to be able to present these data to representatives of the authorities and the community more vividly. We want to emphasize the number of local people with improperly treated or unrecognized CV risk factors who, without the proper preventive programs, will develop complications or die from CVD. 
Table 4. Prediction of lifetime benefit using the lifetime-perspective model for individualizing cardiovascular disease prevention strategies in apparently healthy people (LIFE-CVD) in the appropriate study population.

\begin{tabular}{|c|c|c|c|}
\hline Prevention Strategy & CV Risk Classes & $n$ & $\begin{array}{c}\text { Probability of Survival Free of } \\
\text { Heart Attack or Stroke-Increase in Life Years } \\
\text { in Relation to the Baseline } \\
\text { Mean }(95 \% \mathrm{CI})\end{array}$ \\
\hline \multirow{5}{*}{$\begin{array}{l}\text { Model } 1 \\
\text { Optimal }\end{array}$} & Low & 70 & $0.97(0.68-1.27)$ \\
\hline & Moderate & 182 & 1.58 (1.38-1.77) \\
\hline & High & 114 & $2.40(2.06-2.73)$ \\
\hline & Very high & 103 & $3.06(2.66-3.46)$ \\
\hline & Total & 469 & $2.01(1.85-2.17)$ \\
\hline \multirow{5}{*}{$\begin{array}{c}\text { Model } 2 \\
\text { Moderate }\end{array}$} & Low & 70 & $0.59(0.47-0.72)$ \\
\hline & Moderate & 182 & $0.71(0.63-0.79)$ \\
\hline & High & 114 & $0.95(0.81-1.10)$ \\
\hline & Very high & 103 & $1.08(0.92-1.25)$ \\
\hline & Total & 469 & $0.83(0.77-0.90)$ \\
\hline \multirow{5}{*}{$\begin{array}{l}\text { Model } 3 \\
\text { Minimal }\end{array}$} & Low & 70 & $1.06(0.80-1.32)$ \\
\hline & Moderate & 182 & $1.17(1.01-1.34)$ \\
\hline & High & 114 & $1.21(0.98-1.45)$ \\
\hline & Very high & 103 & 1.37 (1.12-1.63) \\
\hline & Total & 469 & $1.21(1.10-1.32)$ \\
\hline
\end{tabular}

The data are shown as means and $95 \%$ confidence intervals (95\% CI). MI, myocardial infarction; CV, cardiovascular; BPs, systolic blood pressure; TC, total cholesterol; LDL-C, low-density lipoprotein cholesterol. Model 1: optimal prevention strategy: BPs $<130 \mathrm{mmHg}$, LDL-C in low CV risk class $<116 \mathrm{mg} / \mathrm{dL}$, in moderate $\mathrm{CV}$ risk class $<100 \mathrm{mg} / \mathrm{dL}$, in high $\mathrm{CV}$ risk class $<70 \mathrm{mg} / \mathrm{dL}$, in very high $\mathrm{CV}$ risk class $<55 \mathrm{mg} / \mathrm{dL}$, smoking cessation; Model 2: moderate prevention strategy: BPs lowering by $10 \mathrm{mmHg}$ when $>140 \mathrm{mmHg}$, LDL-C lowering by $25 \%$ when low CV risk class $>116 \mathrm{mg} / \mathrm{dL}$, in moderate CV risk class $>100 \mathrm{mg} / \mathrm{dL}$, in high $\mathrm{CV}$ risk class $>70 \mathrm{mg} / \mathrm{dL}$, in very high $\mathrm{CV}$ risk class $>55 \mathrm{mg} / \mathrm{dL}$; Model 3: minimal prevention strategy: TC lowering by $10 \%$, LDL-C lowering by $10 \%$, BPs lowering by $5 \mathrm{mmHg}$, smoking cessation.
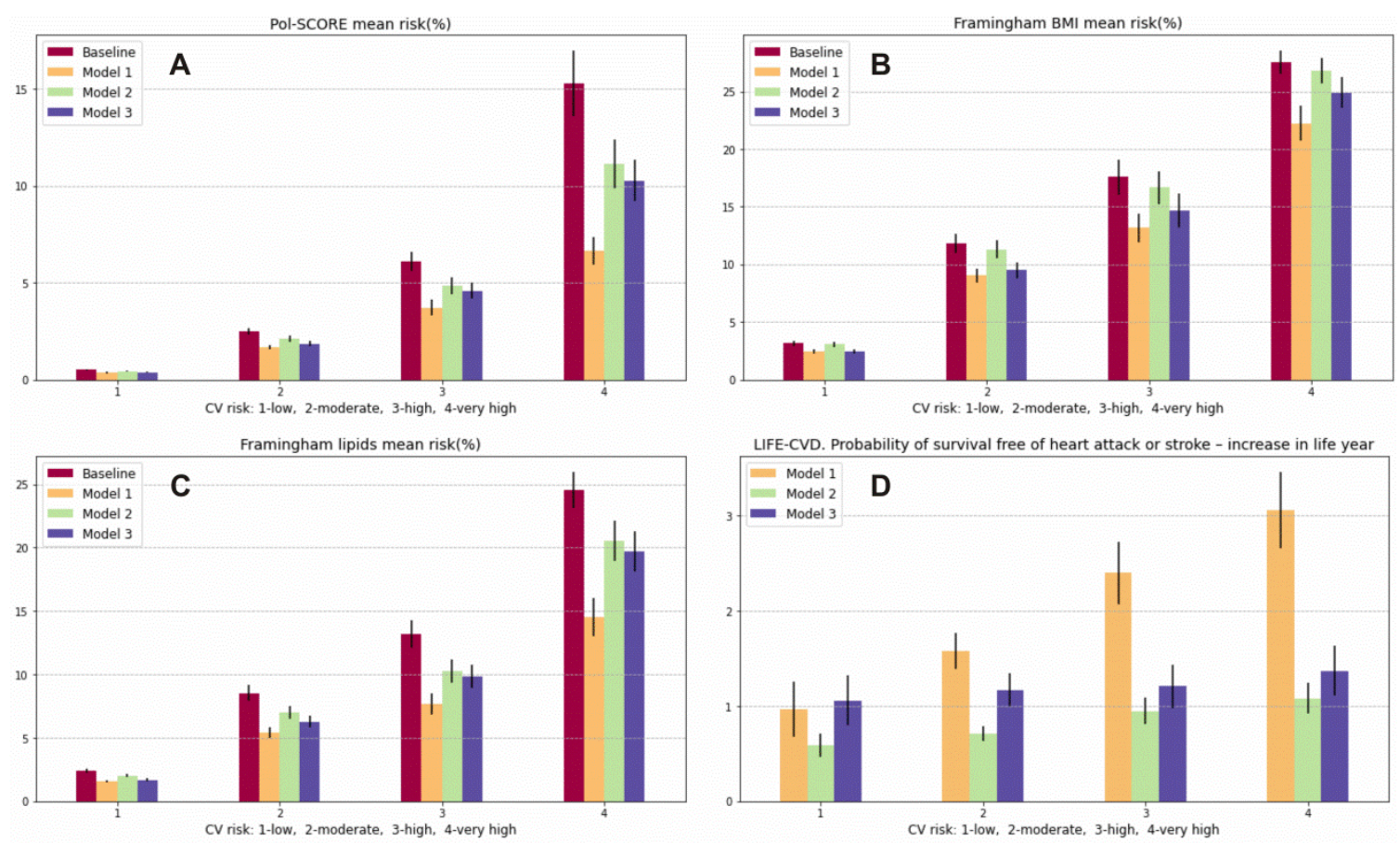

Figure 3. Prediction of 10-year risk of fatal CVD (Pol-SCORE): (A), prediction of 10-year risk of developing a first CVD event (Framingham Cardiovascular Disease) using the lipid model (B) and the 
BMI model; (C), probability of survival-free heart attack or stroke-increase in life years (LIFE-CVD) (D). Variables are presented as means and 95\% confidence interval (95\% CI).

Table 5. Estimated number of local the inhabitants who would survive (Pol-SCORE) or who would not develop a first CVD event within 10 years (Cardiovascular Disease Framingham Heart Study) or who would not develop MI, stroke, or CV death (lifetime-perspective model for individualizing cardiovascular disease prevention strategies in apparently healthy people LIFE-CVD) within 10 years or within their lifetime after applying prevention strategies.

\begin{tabular}{|c|c|c|c|c|c|}
\hline SCORES & & Baseline & Model 1 & Model 2 & Model 3 \\
\hline \multirow{2}{*}{ Pol-SCORE } & Deceased & 3963 & 2177 & 3095 & 2815 \\
\hline & Survivors & - & 1786 & 868 & 1148 \\
\hline \multirow[b]{2}{*}{ FRS_Lipids } & First CVD event within 10 years & 13,148 & 7987 & 10,734 & 9880 \\
\hline & $\begin{array}{l}\text { Stay free of developing the first } \\
\text { CVD event within } 10 \text { years }\end{array}$ & - & 5161 & 2414 & 3268 \\
\hline \multirow[b]{2}{*}{ FRS-BMI } & First CVD event within 10 years & 16,727 & 12,835 & 16,069 & 13,927 \\
\hline & $\begin{array}{l}\text { Stay free of developing the first } \\
\text { CVD event within } 10 \text { years }\end{array}$ & - & 3892 & 658 & 2800 \\
\hline \multirow{2}{*}{$\begin{array}{l}\text { LIFE-CVD } \\
\text { 10-year risk }\end{array}$} & $\begin{array}{l}\text { First MI, stroke, or CV death } \\
\text { within } 10 \text { years }\end{array}$ & 4934 & 2534 & 3738 & 3748 \\
\hline & $\begin{array}{l}\text { Stay free of developing the first } \\
\text { CVD event within } 10 \text { years }\end{array}$ & - & 2400 & 1196 & 1186 \\
\hline \multirow{2}{*}{$\begin{array}{l}\text { LIFE-CVD } \\
\text { lifetime risk }\end{array}$} & $\begin{array}{c}\text { First MI, stroke, or CV death } \\
\text { within lifetime }\end{array}$ & 17,461 & 10,186 & 13,640 & 13,899 \\
\hline & $\begin{array}{l}\text { Stay free of developing the first } \\
\text { CVD event within lifetime }\end{array}$ & - & 7275 & 3821 & 3562 \\
\hline
\end{tabular}

BMI, body mass index; BPs, systolic blood pressure; CV, cardiovascular; CVD, cardiovascular disease, $\mathrm{TC}$, total cholesterol; FRS, Cardiovascular Disease Framingham Heart Study; SCORE Systematic Coronary Risk Estimation. Model 1: optimal prevention strategy: $\mathrm{BPs}<130 \mathrm{mmHg}, \mathrm{TC}<156 \mathrm{mg} / \mathrm{dL}, \mathrm{BMI}<25$, smoking cessation; Model 2: moderate prevention strategy: BPs lowering by $10 \mathrm{mmHg}$ when $>140 \mathrm{mmHg}$, TC lowering by $25 \%$ when $>190 \mathrm{mg} / \mathrm{dL}, \mathrm{BMI}<30$. Model 3: minimal prevention strategy: TC lowering by $10 \%$, BPs lowering by $5 \mathrm{mmHg}$, BMI lowering by $5 \%$, smoking cessation.

Table 6. Estimated cardiovascular disease burden in the local population.

\begin{tabular}{|c|c|c|c|c|c|}
\hline \multirow{2}{*}{ Variable } & \multirow{2}{*}{ Total Population } & \multicolumn{4}{|c|}{ Cardiovascular Risk Class } \\
\hline & & Low & Moderate & High & Very High \\
\hline Local population & 204,511 & 98,378 & 44,434 & 26,476 & 35,223 \\
\hline History of hypertension & 58,283 & 7173 & 15,995 & 12,394 & 22,721 \\
\hline $\begin{array}{l}\text { Uncontrolled BP in patients } \\
\text { diagnosed with hypertension * }\end{array}$ & 41,934 & 4767 & 11,286 & 8644 & 17,237 \\
\hline Undiagnosed hypertension & 77,746 & 40,470 & 19,782 & 8409 & 9085 \\
\hline History of hypercholesterolemia & 60,829 & 12,521 & 20,005 & 11,669 & 16,634 \\
\hline $\begin{array}{l}\text { Uncontrolled lipid profile in } \\
\text { patients with diagnosed } \\
\text { hypercholesterolemia }\end{array}$ & 53,370 & 10,504 & 15,674 & 10,996 & 16,196 \\
\hline $\begin{array}{c}\text { Undiagnosed } \\
\text { hypercholesterolemia }\end{array}$ & 91,293 & 36,790 & 22,168 & 14,175 & 18,160 \\
\hline History of diabetes & 15,220 & 512 & 3720 & 2930 & 8058 \\
\hline
\end{tabular}


Table 6. Cont.

\begin{tabular}{|c|c|c|c|c|c|}
\hline \multirow{2}{*}{ Variable } & \multirow{2}{*}{ Total Population } & \multicolumn{4}{|c|}{ Cardiovascular Risk Class } \\
\hline & & Low & Moderate & High & Very High \\
\hline $\begin{array}{l}\text { Uncontrolled glucose in patients } \\
\text { diagnosed with diabetes }\end{array}$ & 4493 & 256 & 457 & 1119 & 2661 \\
\hline Undiagnosed diabetes $* * * * *$ & 522 & 0 & 257 & 265 & 0 \\
\hline
\end{tabular}

BP: blood pressure; BPs: systolic blood pressure; BPd: diastolic blood pressure; CV: cardiovascular; HbA1c: hemoglobin A1c; LDL: low-density lipoprotein; TC: total cholesterol. ${ }^{*} \mathrm{BPs}<130$ and $\mathrm{BPd}<80 \mathrm{mmHg}$ below 65 years old, BPs $<140$ and BPd $<80 \mathrm{mmHg} 65-80$ years old, BPs $<150$ and $\mathrm{BPd}<80 \mathrm{mmHg}$ over 80 years old. ${ }^{* *}$ LDL-c $<116 \mathrm{mg} / \mathrm{dL}$ in low CV class, $<100 \mathrm{mg} / \mathrm{dL}$ in moderate CV class, $<70 \mathrm{mg} / \mathrm{dL}$ in high CV class, $<55 \mathrm{mg} / \mathrm{dL}$ in very high CV class. ${ }^{* * *} \mathrm{TC}>190 \mathrm{mg} / \mathrm{dL}$ or LDL-c $>116 \mathrm{mg} / \mathrm{dL}$ in low CV class, $>100 \mathrm{mg} / \mathrm{dL}$ in moderate CV class, $>70 \mathrm{mg} / \mathrm{dL}$ in high CV class, $>55 \mathrm{mg} / \mathrm{dL}$ in very high CV class. ${ }^{* * * *} \mathrm{HbA} 1 \mathrm{c}<7.0 \% .{ }^{* * * *}$ Fasting glucose $\geq 126 \mathrm{mg} / \mathrm{dL}$ or OGGT $120 \mathrm{~min}$ glucose $\geq 200 \mathrm{mg} / \mathrm{dL}$.

\section{Discussion}

CVD is still a major cause of death and disability in European countries [1], including in Poland [14,15]. CVD is often silent and may occur suddenly [16,17], underscoring the importance of primary prevention. Estimating risk reduction using prevention strategies of various levels of intensity can help local authorities select or design prevention programs. Our findings highlight applying the minimal strategy to the overall population without previously diagnosed CVD is a more effective primarily prevention strategy than the application of the moderate strategy to the population with increased risk factors. Moreover, applying the minimal strategy to the low CV risk category would be more beneficial than following the optimal model.

\subsection{Prevention Strategies}

We have designed three different prevention models. The optimal model assumed the treatment thresholds for risk factors according to the European guidelines [2,18]. However, it is known that only a small number of the population is able to achieve the optimal therapy and target risk factor values. In the Polish population, only $10.9 \%$ of patients with hypercholesterolemia have achieved a total cholesterol level below $4.9 \mathrm{mmol} / \mathrm{L}$, and only $5.4 \%$ have controlled comorbid hypertension and hypercholesterolemia [19]. Therefore, we designed other models. The moderate model assumed lowered BPs in people with hypertension, lowering the cholesterol level in people with hypercholesterolemia using moderate doses of the usual single drug $[20,21]$, and eliminating obesity.

In Poland, over $40 \%$ of people with $\mathrm{AH}$ and $60 \%$ of people with hypercholesterolemia are not aware of their condition [22]. The minimal intervention model, which is based on lifestyle modification regardless of the baseline parameters, was designed for the entire analyzed population according to the criteria of each of the CV scales mentioned. In accordance with earlier surveys, a sodium reduction of about $1.75 \mathrm{~g}$ per day was associated with a reduction of $4.2 / 2.1 \mathrm{mmHg}$ in $\mathrm{BPs} / \mathrm{BPd}$ [23]. In obese people, every $10 \mathrm{~kg}$ reduction in body weight reduces LDL-C by $8 \mathrm{mg} / \mathrm{dL}$ [24,25]. Additionally, the Mediterranean diet significantly reduced BP and lipid levels. Adjusted changes from baseline in BPs were -2.3 $(95 \% \mathrm{CI}-4.0,-0.5) \mathrm{mmHg}$ and $-2.6(95 \% \mathrm{CI}-4.3,-0.9) \mathrm{mmHg}$ in the Mediterranean diet with olive oil and the Mediterranean diet with nuts, respectively. Mean changes from baseline TC were $-11.3,-13.6$, and $-4.4 \mathrm{mg} / \mathrm{dL}$ in the Mediterranean diet with olive oil and nuts, respectively [26]. Exercise has significant average effects on BPs and BPd [27,28]: aerobic training reduced BPs by $-4(95 \% \mathrm{CI},-5$ to -2$) \mathrm{mmHg}$ and $\mathrm{BPd}$ by $-3(95 \% \mathrm{CI}$, -3 to -2$) \mathrm{mmHg}$; resistance training reduced $\mathrm{BPs}$ by $-2(95 \% \mathrm{CI},-4$ to 0$) \mathrm{mmHg}$ and $\mathrm{BPd}$ by $-3(95 \% \mathrm{CI},-5$ to -2$) \mathrm{mmHg}$, and combined training reduced $\mathrm{BP}$ by $-3(95 \% \mathrm{CI},-4$ to $-2) \mathrm{mmHg}$ and BPd by $-3(95 \% \mathrm{CI},-3$ to 0$) \mathrm{mmHg}$. The effects of exercise on cholesterol have also been studied. Resistance training significantly reduced LDL-c by 6 (95\% CI, -11 to -1$) \mathrm{mg} / \mathrm{dL}$ [29]. On this basis, the minimal prevention strategy in the current study 
assumed a reduction in TC and LDL-C by 10\%, BPs by $5 \mathrm{mmHg}$, BMI by $5 \%$, and smoking cessation in all participants.

\subsection{Estimating the Effects of Preventative Models}

The prevention of primary CVD remains a significant challenge. By using the optimal prevention strategy, we should be able to obtain the best possible results for reducing $\mathrm{CV}$ risk. However, it is known that only a small number of the population achieves the optimal therapy and target risk factor values. In the EUROASPIRE V survey of primary prevention in Europe, risk factor control was poor in $43.5 \%$ of the patients with obesity; a total of $47 \%$ of patients on BP-lowering medication and $46.9 \%$ of dyslipidemic patients who were being treated for their condition reached their targets [4]. Patients with increased CV risk factors should be actively searched for and should have access to programs delivered by healthcare professionals, such as physicians, nurses, physiotherapists, dieticians, or physical activity specialists, that address all aspects of lifestyle (BP, lipids, glucose, physical activity, and adherence to medications) to reduce the risk of CV events. Despite the high involvement of healthcare professionals, risk reduction would still be lower than it would be in the proposed minimal intervention model. There is still a significant difference between evidence-based guidelines and daily clinical practice.

Our findings highlight that the minimal strategy applied to the overall population without CVD could be more effective than the moderate (realistic) strategy applied in the population with abnormal test results regardless of their CV risk category; even in the low $\mathrm{CV}$ risk category, the minimal intervention would be more beneficial than it would be the optimal one. It is worth emphasizing that almost half of the population belongs to the lowrisk category. In general, CVD events occur after middle age, while most young adults have a low 10-year CVD risk. However, the early prevention of risk-modifying strategies can result in greater lifetime therapy benefits [30]. The LIFE-CVD [12] model provides a greater time-horizon than 10 years; hence, we could compare the effects of the assumed models not only in a 10-year interval but at a longer interval. Furthermore, lifetime estimates could be more comprehensive and approachable for patients or health providers. While using this model in the low CV risk category, non-pharmacological methods reduced the incidence of CVD more than the proposed optimal model in addition to the moderate preventative model. This study helped us to gain insights into the individual effects of prevention strategies and suggests that more attention should be paid to primary prevention for the entire population, which was also confirmed by Ma [31]. Environmental approaches involve the use of policy and structural changes to create environments where health is promoted and healthy choices are reinforced. Changes that make healthy behaviors easier and more convenient for individuals should be made to social and physical environments while maintaining broad reach and sustaining health benefits for the overall population. Environmental strategies that can help to reduce the $\mathrm{CV}$ risk factors include creating smoke-free environments and increasing access to healthier foods, including those with less sodium.

\subsection{Strengths and Limitations}

This study is limited by a sample from one region, which is an urban environment that may not be fully representative. For the calculation of the effects of particular strategies, we used scores used in primary prevention, whereas very high-risk individuals might have benefits similar to those seen in secondary prevention. Therefore, the results might underestimate the CVD risk population while simultaneously underestimating the effects of the interventions. The LIFE-CVD model uses the parental history of MI prior to age 60. In our data, we obtained information about the parental history of MI prior to age 50 . Despite these limitations, there are some advantages to the study. We used data collected from a random sample of local citizens. The variables were collected using standardized questionnaires, methods, and equipment. The CV risk classes were carefully evaluated 
according to the latest recommendations: 2019 ESC/EAS guidelines for the management of dyslipidemias: lipid modification to reduce cardiovascular risk [2].

\section{Conclusions}

The percentages of the low, moderate, high, and very high CV risk classes in the general population are $46.1 \%, 22.8 \%, 13.5 \%$, and $17.6 \%$, respectively. A minimum strategy applied to the entire population without CVD may be more effective than a strategy that focuses on the moderate pharmacological treatment of individual risk factors, regardless of the initial CV risk category. In the low CV risk category, minimal (non-pharmacological lifestyle) intervention may be more favorable than optimal intervention. This suggests that the application of general principles of primary prevention, i.e., weight loss, diet modification, smoking cessation, and exercise, could produce better results than restricting treatment to patients with high $\mathrm{BP}$ and cholesterol levels. $\mathrm{CV}$ prevention requires modern prophylaxis programs that are adapted to medical and cultural conditions. Improvements in these areas can help create an environment in which people can receive high-quality care, make healthier choices, and take control of their health. These data could be relevant to public health institutions designing $\mathrm{CV}$ prevention strategies.

Author Contributions: Conceptualization, M.C., J.J., W.Ł. and K.A.K.; methodology, M.C., P.S., J.J., W.Ł. and K.A.K.; software, A.R.; validation, K.A.K.; formal analysis, J.J. and W.Ł.; investigation, M.C., M.D., P.S., A.S., M.Ł., N.Z. and M.Z.; resources K.A.K. and A.R.; data curation A.R.; writing—original draft preparation, M.C. and J.J.; writing—review and editing, M.C., J.J., W.Ł. and K.A.K.; visualization, M.C., J.J. and W.Ł.; supervision, K.A.K.; project administration, K.A.K.; funding acquisition, A.R. and K.A.K. All authors have read and agreed to the published version of the manuscript.

Funding: This research was funded by the Municipal Office in Bialystok, grant number W/UB/DSP/ 1640/UMBIAŁYSTOK/2017, and from statutory funds from the Medical University of Bialystok for the Bialystok PLUS study, grant number SUB/1/00/19/001/1201.

Institutional Review Board Statement: Ethical approval for this study was provided by the Ethics Committee of the Medical University of Bialystok (Poland) on 31 March 2016 (approval number: R-I-002/108/2016). The study was conducted in accordance with the Declaration of Helsinki.

Informed Consent Statement: All participants gave written informed consent.

Data Availability Statement: The data set we generated during and/or analyzed during the current study are not publicly available due to confidentiality issues but are available from the corresponding author on request.

Acknowledgments: The authors thank Tomasz Zdrojewski, Jakub Stokwiszewski, and Kamil Chwojnicki for providing the algorithm for the Pol-SCORE.

Conflicts of Interest: The authors declare no conflict of interest.

\section{References}

1. Townsend, N.; Nichols, M.; Scarborough, P.; Rayner, M. Cardiovascular disease in Europe 2015: Epidemiological update. Eur. Heart J. 2015, 36, 2673-2674. [CrossRef] [PubMed]

2. Mach, F.; Baigent, C.; Catapano, A.L.; Koskinas, K.C.; Casula, M.; Badimon, L.; Chapman, M.J.; De Backer, G.G.; Delgado, V.; Ference, B.A.; et al. 2019 ESC/EAS Guidelines for the management of dyslipidaemias: Lipid modification to reduce cardiovascular risk. Eur. Heart J. 2020, 41, 111-188. [CrossRef] [PubMed]

3. Piepoli, M.F.; Hoes, A.W.; Agewall, S.; Albus, C.; Brotons, C.; Catapano, A.L.; Cooney, M.T.; Corra, U.; Cosyns, B.; Deaton, C.; et al. 2016 European Guidelines on cardiovascular disease prevention in clinical practice: The Sixth Joint Task Force of the European Society of Cardiology and Other Societies on Cardiovascular Disease Prevention in Clinical Practice (constituted by representatives of 10 societies and by invited experts)Developed with the special contribution of the European Association for Cardiovascular Prevention \& Rehabilitation (EACPR). Eur. Heart J. 2016, 37, 2315-2381. [CrossRef]

4. Kotseva, K.; De Backer, G.; De Bacquer, D.; Ryden, L.; Hoes, A.; Grobbee, D.; Maggioni, A.; Marques-Vidal, P.; Jennings, C.; Abreu, A.; et al. Primary prevention efforts are poorly developed in people at high cardiovascular risk: A report from the European Society of Cardiology EURObservational Research Programme EUROASPIRE V survey in 16 European countries. Eur. J. Prev. Cardiol. 2021, 28, 370-379. [CrossRef] 
5. Kotseva, K.; De Backer, G.; De Bacquer, D.; Ryden, L.; Hoes, A.; Grobbee, D.; Maggioni, A.; Marques-Vidal, P.; Jennings, C.; Abreu, A.; et al. Lifestyle and impact on cardiovascular risk factor control in coronary patients across 27 countries: Results from the European Society of Cardiology ESC-EORP EUROASPIRE V registry. Eur. J. Prev. Cardiol. 2019, 26, 824-835. [CrossRef]

6. Jankowski, P.; Kosior, D.A.; Sowa, P.; Szostak-Janiak, K.; Koziel, P.; Krzykwa, A.; Sawicka, E.; Haberka, M.; Setny, M.; Kaminski, K.; et al. Secondary prevention of coronary artery disease in Poland. Results from the POLASPIRE survey. Cardiol. J. 2020, 27, 533-540. [CrossRef]

7. Chlabicz, M.; Jamiolkowski, J.; Paniczko, M.; Sowa, P.; Szpakowicz, M.; Lapinska, M.; Jurczuk, N.; Kondraciuk, M.; PtaszynskaKopczynska, K.; Raczkowski, A.; et al. ECG Indices Poorly Predict Left Ventricular Hypertrophy and Are Applicable Only in Individuals with Low Cardiovascular Risk. J. Clin. Med. 2020, 9, 1364. [CrossRef]

8. Chlabicz, M.; Jamiolkowski, J.; Laguna, W.; Sowa, P.; Paniczko, M.; Lapinska, M.; Szpakowicz, M.; Drobek, N.; Raczkowski, A.; Kaminski, K.A. A Similar Lifetime CV Risk and a Similar Cardiometabolic Profile in the Moderate and High Cardiovascular Risk Populations: A Population-Based Study. J. Clin. Med. 2021, 10, 1584. [CrossRef]

9. Zdrojewski, T.; Jankowski, P.; Bandosz, P.; Bartus, S.; Chwojnicki, K.; Drygas, W.; Gaciong, Z.; Hoffman, P.; Kalarus, Z.; Kazmierczak, J.; et al. A new version of cardiovascular risk assessment system and risk charts calibrated for Polish population. Kardiol. Pol. 2015, 73, 958-961. [CrossRef]

10. Conroy, R.M.; Pyorala, K.; Fitzgerald, A.P.; Sans, S.; Menotti, A.; De Backer, G.; De Bacquer, D.; Ducimetiere, P.; Jousilahti, P.; Keil, U.; et al. Estimation of ten-year risk of fatal cardiovascular disease in Europe: The SCORE project. Eur. Heart J. 2003, 24, 987-1003. [CrossRef]

11. D'Agostino, R.B.S.; Vasan, R.S.; Pencina, M.J.; Wolf, P.A.; Cobain, M.; Massaro, J.M.; Kannel, W.B. General cardiovascular risk profile for use in primary care: The Framingham Heart Study. Circulation 2008, 117, 743-753. [CrossRef] [PubMed]

12. Jaspers, N.E.M.; Blaha, M.J.; Matsushita, K.; van der Schouw, Y.T.; Wareham, N.J.; Khaw, K.T.; Geisel, M.H.; Lehmann, N.; Erbel, R.; Jockel, K.H.; et al. Prediction of individualized lifetime benefit from cholesterol lowering, blood pressure lowering, antithrombotic therapy, and smoking cessation in apparently healthy people. Eur. Heart J. 2020, 41, 1190-1199. [CrossRef]

13. Jaspers, N.E.M.; Ridker, P.M.; Dorresteijn, J.A.N.; Visseren, F.L.J. The prediction of therapy-benefit for individual cardiovascular disease prevention: Rationale, implications, and implementation. Curr. Opin. Lipidol. 2018, 29, 436-444. [CrossRef] [PubMed]

14. Kuzma, L.; Struniawski, K.; Pogorzelski, S.; Bachorzewska-Gajewska, H.; Dobrzycki, S. Gender Differences in Association between Air Pollution and Daily Mortality in the Capital of the Green Lungs of Poland-Population-Based Study with 2,953,000 Person-Years of Follow-Up. J. Clin. Med. 2020, 9, 2351. [CrossRef] [PubMed]

15. Gierlotka, M.; Zdrojewski, T.; Wojtyniak, B.; Polonski, L.; Stokwiszewski, J.; Gasior, M.; Kozierkiewicz, A.; Kalarus, Z.; Wierucki, L.; Chlebus, K.; et al. Incidence, treatment, in-hospital mortality and one-year outcomes of acute myocardial infarction in Poland in 2009-2012-nationwide AMI-PL database. Kardiol. Pol. 2015, 73, 142-158. [CrossRef] [PubMed]

16. Ptaszynska-Kopczynska, K.; Sobolewska, D.; Kozuch, M.; Dobrzycki, S.; Sobkowicz, B.; Hirnle, T.; Musial, W.J.; Kaminski, K.A. Efficacy of invasive treatment and the occurrence of cardiac rupture in acute ST-elevation myocardial infarction. Kardiol. Pol. 2011, 69, 795-800.

17. Kubica, J.; Adamski, P.; Paciorek, P.; Ladny, J.R.; Kalarus, Z.; Banasiak, W.; Kochman, W.; Goracy, J.; Wozakowska-Kaplon, B.; Navarese, E.P.; et al. Treatment of patients with acute coronary syndrome: Recommendations for medical emergency teams: Focus on antiplatelet therapies. Updated experts' standpoint. Cardiol. J. 2018, 25, 291-300. [CrossRef]

18. Williams, B.; Mancia, G.; Spiering, W.; Agabiti Rosei, E.; Azizi, M.; Burnier, M.; Clement, D.L.; Coca, A.; de Simone, G.; Dominiczak, A.; et al. 2018 ESC/ESH Guidelines for the management of arterial hypertension. Eur. Heart J. 2018, 39, 3021-3104. [CrossRef]

19. Niklas, A.; Marcinkowska, J.; Kozela, M.; Pajak, A.; Zdrojewski, T.; Drygas, W.; Piwonska, A.; Kwasniewska, M.; Kozakiewicz, K.; Tykarski, A. Blood pressure and cholesterol control in patients with hypertension and hypercholesterolemia: The results from the Polish multicenter national health survey WOBASZ II. Pol. Arch. Intern. Med. 2019, 129, 864-873. [CrossRef]

20. Nawrocki, J.W.; Weiss, S.R.; Davidson, M.H.; Sprecher, D.L.; Schwartz, S.L.; Lupien, P.J.; Jones, P.H.; Haber, H.E.; Black, D.M Reduction of LDL cholesterol by $25 \%$ to $60 \%$ in patients with primary hypercholesterolemia by atorvastatin, a new HMG-CoA reductase inhibitor. Arterioscler. Thromb. Vasc. Biol. 1995, 15, 678-682. [CrossRef]

21. Materson, B.J.; Reda, D.J.; Cushman, W.C.; Massie, B.M.; Freis, E.D.; Kochar, M.S.; Hamburger, R.J.; Fye, C.; Lakshman, R.; Gottdiener, J.; et al. Single-drug therapy for hypertension in men. A comparison of six antihypertensive agents with placebo. The Department of Veterans Affairs Cooperative Study Group on Antihypertensive Agents. N. Engl. J. Med. 1993, 328, 914-921. [CrossRef] [PubMed]

22. Niklas, A.; Flotynska, A.; Puch-Walczak, A.; Polakowska, M.; Topor-Madry, R.; Polak, M.; Piotrowski, W.; Kwasniewska, M.; Nadrowski, P.; Pajak, A.; et al. Prevalence, awareness, treatment and control of hypertension in the adult Polish population-Multicenter National Population Health Examination Surveys-WOBASZ studies. Arch. Med. Sci. 2018, 14, 951-961. [CrossRef]

23. Elliott, P.; Stamler, J.; Nichols, R.; Dyer, A.R.; Stamler, R.; Kesteloot, H.; Marmot, M. Intersalt revisited: Further analyses of 24 hour sodium excretion and blood pressure within and across populations. Intersalt Cooperative Research Group. BMJ 1996, 312 1249-1253. [CrossRef] [PubMed]

24. Dattilo, A.M.; Kris-Etherton, P.M. Effects of weight reduction on blood lipids and lipoproteins: A meta-analysis. Am. J. Clin. Nutr 1992, 56, 320-328. [CrossRef] [PubMed]

25. Zomer, E.; Gurusamy, K.; Leach, R.; Trimmer, C.; Lobstein, T.; Morris, S.; James, W.P.; Finer, N. Interventions that cause weight loss and the impact on cardiovascular risk factors: A systematic review and meta-analysis. Obes. Rev. 2016, 17, 1001-1011. [CrossRef] 
26. Domenech, M.; Roman, P.; Lapetra, J.; Garcia de la Corte, F.J.; Sala-Vila, A.; de la Torre, R.; Corella, D.; Salas-Salvado, J.; RuizGutierrez, V.; Lamuela-Raventos, R.M.; et al. Mediterranean diet reduces 24-hour ambulatory blood pressure, blood glucose, and lipids: One-year randomized, clinical trial. Hypertension 2014, 64, 69-76. [CrossRef]

27. Cornelissen, V.A.; Smart, N.A. Exercise training for blood pressure: A systematic review and meta-analysis. J. Am. Heart Assoc. 2013, 2, e004473. [CrossRef]

28. Corso, L.M.; Macdonald, H.V.; Johnson, B.T.; Farinatti, P.; Livingston, J.; Zaleski, A.L.; Blanchard, A.; Pescatello, L.S. Is Concurrent Training Efficacious Antihypertensive Therapy? A Meta-analysis. Med. Sci. Sports Exerc. 2016, 48, 2398-2406. [CrossRef]

29. Kelley, G.A.; Kelley, K.S. Impact of progressive resistance training on lipids and lipoproteins in adults: Another look at a meta-analysis using prediction intervals. Prev. Med. 2009, 49, 473-475. [CrossRef]

30. Ferket, B.S.; van Kempen, B.J.; Heeringa, J.; Spronk, S.; Fleischmann, K.E.; Nijhuis, R.L.; Hofman, A.; Steyerberg, E.W.; Hunink, M.G. Personalized prediction of lifetime benefits with statin therapy for asymptomatic individuals: A modeling study. PLoS Med. 2012, 9, e1001361. [CrossRef]

31. Ma, M.; Dollar, K.M.; Kibler, J.L.; Sarpong, D.; Samuels, D. The effects of priming on a public health campaign targeting cardiovascular risks. Prev. Sci. 2011, 12, 333-338. [CrossRef] [PubMed] 